\title{
Mídia e democracia no Brasil: relações entre o sistema de mídia e o sistema político
}

\author{
Fernando Antônio Azevedo \\ Universidade Federal de São Carlos
}

\begin{abstract}
Resumo
Utilizando os modelos de análise propostos por Hallim e Mancini para comparar sistemas de mídia e sistemas políticos, o artigo descreve, classifica e discute o sistema de mídia brasileiro e sua relação com o sistema político no atual período democrático tendo como foco o comportamento do jornalismo político. São enfatizadas na análise as coberturas eleitorais da chamada grande imprensa durante as eleições presidenciais (1989, 1994, 1998 e 2002) e as mudanças operadas do ponto de vista da diversidade externa e interna do sistema de mídia, bem como da sua capacidade de promover o debate pluralista.
\end{abstract}

Palavras-chave: mídia de massa, imprensa, monopólio, democracia.

\begin{abstract}
Using Hallim and Mancini's models of analysis to compare media and political systems, the article describes, classifies and discusses the brazilian case in the recent democratic period, having as focus the political jornalism behaviour. The electoral press coverage during the presidential elections (1989, 1994, 1998 and 2002) and the changes in regard to external and internal diversity of the media system are emphasized, as well as its capacity to promote a pluralist debate.
\end{abstract}

Key words: mass media, press, monopoly, democracy. 
O sistema de mídia brasileiro vis-à-vis o sistema político apresenta um conjunto de características que permitem classificá-lo, de acordo com os modelos propostos por Hallim e Mancini, como um sistema mediterrâneo ou pluralista polarizado.

Historicamente algumas das características mais notáveis do nosso sistema de mídia permanecem imutáveis: o monopólio familiar e a propriedade cruzada nos meios de comunicação de massa, a pequena diversidade externa do ponto de vista político e o viés conservador, a baixa circulação dos jornais associada ao baixo número de leitores e, como conseqüência, no campo da grande imprensa, um jornalismo orientado prioritariamente para as elites e permeável à influência dos públicos fortes. Deve-se lembrar ainda o surgimento tardio da imprensa e dos jornais comerciais em nosso país e a centralidade e hegemonia da televisão em nosso sistema de mídia. Some-se a tudo isto, no campo político, os ciclos autoritários, o retorno relativamente recente da democracia e da liberdade de imprensa e a atual presença de um pluralismo polarizado (moderado) e teremos um quadro que em características mais gerais se encaixam perfeitamente, tanto no que diz respeito ao sistema de mídia quanto ao sistema político, no modelo mediterrâneo.

A análise que desenvolvo neste texto sobre os meios de comunicação de massa, em específico o jornalismo político e seu papel de mediação particularmente nos períodos eleitorais, baseia-se nos modelos propostos por Hallim e Mancini (2004) que analisam a relação entre sistemas de mídia e sistemas políticos. Estes modelos, batizado pelos autores como pluralista polarizado (ou mediterrâneo), corporativista-democrático (ou norte-centro europeu) e liberal (ou Atlântico Norte) foram construídos a partir da análise de algumas dimensões consideradas críticas para definir as características desses sistemas. Para caracterizar um sistema de mídia os autores definiram quatro dimensões analíticas: mercado de mídia, paralelismo político, desenvolvimento do jornalismo profissional e o grau e a natureza da intervenção estatal no campo da comunicação. A primeira dimensão está relacionada ao desenvolvimento forte ou fraco da mídia de massa no mercado de informação; a segunda, à natureza da relação entre a imprensa, governos, ideologias e partidos; a terceira, ao grau de profissionalismo do jornalismo e, finalmente, a última à capacidade de intervenção e regulamentação do Estado no setor das comunicações.

Em relação ao sistema político, os autores elegeram como dimensões fundamentais a história política (padrões de conflito e consenso), o modelo democrático adotado (majoritário ou proporcional), os valores políticos (pluralismo versus individualismo), as funções do Estado e a presença de regras do tipo legal-racional nos processos de regulação e governança. Basicamente, cada caso empírico é definido pelo cruzamento das características do sistema de mídia e do sistema político. 
Contudo, os autores advertem o leitor, com a devida e necessária ênfase, que são modelos ideais do tipo weberiano. Ou seja, no mundo real e empírico, tanto o sistema de mídia quanto o sistema político não apresentam o mesmo grau de pureza dos modelos propostos e devem ser classificados pela sua proximidade com um dos modelos ideais, podendo, inclusive, mesclar atributos de mais de um modelo ou estar em processo de transição de um modelo para outro. Aliás, lembram também os autores que os próprios sistemas de mídia não são estáticos e que estão em permanente processo de mudança. Endossando fortemente todas estas advertências, resumo, a seguir, as características básicas de cada modelo.

O modelo pluralista polarizado, exemplificado pelos casos da França, Grécia, Itália, Portugal e Espanha (daí o nome 'mediterrâneo') apresenta como principais elementos do seu sistema de mídia jornais com baixa circulação e orientados predominantemente para a elite política e a centralidade da mídia eletrônica (rádio e TV) no mercado de informação. A liberdade de imprensa e o desenvolvimento da mídia comercial são relativamente tardios e recentes, e os jornais freqüentemente são frágeis do ponto de vista econômico, dependentes de subsídios e ajuda governamental (via publicidade oficial) para sobreviver. Há alguma diversidade externa, mas o paralelismo político é alto, com a predominância de um jornalismo opinativo orientado para a defesa de interesses ideológicos, políticos e econômicos ou, em casos mais extremos, simplesmente a serviço de governos, partidos ou grupos econômicos. O sistema público de televisão, quando existente, tende a apoiar as políticas de governo e o profissionalismo no campo jornalístico é de desenvolvimento relativamente recente. Não há, também, um claro predomínio das regras legal-racionais na regulação do setor da comunicação. No que diz respeito ao sistema político, esse modelo trata como características básicas períodos de autoritarismo e democratização recente e/ou pluralismo polarizado, a forte presença dos partidos políticos na vida pública, o predomínio da representação coletiva sobre a individual, o forte envolvimento do Estado e dos partidos na economia (dirigismo) e, em alguns lugares (França e Itália), a presença de um welfare state.

O modelo corporativista-democrático, que tipifica os sistemas de mídia de países como Dinamarca, Suécia, Noruega, Finlândia, Alemanha e Suíça, possui como elementos constitutivos um desenvolvimento precoce da indústria jornalística e da liberdade de imprensa, uma alta circulação dos jornais e uma imprensa fortemente ligada a grupos sociais organizados, embora essa ligação venha sofrendo declínio desde a década de 1970. Por conta dessa última característica, historicamente o jornalismo apresenta um alto grau de paralelismo político, um moderado grau de diversidade externa e, embora se mantenha o legado de um jornalismo de opinião, é crescente a ênfase no jornalismo de informação. $O$ profissionalismo no campo jornalístico é elevado e a mídia é vista pelos cidadãos 
como uma instituição social importante que o Estado deve proteger garantindo a liberdade de imprensa. Ao mesmo tempo, há uma forte regulação do setor pelo governo através de regras do tipo racional-legal. Na área da mídia eletrônica coexiste um sistema público de televisão, no qual partidos e organizações sociais possuem grande influência, e a televisão comercial com vigorosa presença no mercado de informação. Em resumo, o sistema de mídia desse modelo combina empresas jornalísticas comerciais fortes com uma imprensa historicamente ligada a grupos sociais e políticos, possibilitando, assim, que o alto grau de paralelismo político coexista com um alto grau de profissionalismo político e que a tradição liberal de liberdade de imprensa conviva com a alta capacidade de regulação do Estado no setor da informação. Do ponto de vista do sistema político, as características básicas incluem um Estado do tipo welfare, grupos sociais enraizados e organizados, instituições liberais de longa tradição e solidez e uma história política pluralista moderada (com grande diversidade ideológica, mas com alto grau de consenso sobre a natureza do regime político) e democrática (com a exceção da Áustria e Alemanha, cujas instituições liberais só foram construídas após a II Grande Guerra).

O modelo liberal, típico dos Estados Unidos, Canadá e Inglaterra, caracteriza-se pelo desenvolvimento precoce de uma imprensa comercial e de massa num ambiente marcado desde cedo pela liberdade de imprensa e pelo individualismo. Nesse contexto, o paralelismo político é baixo e a diversidade interna bastante alta (com exceção da Inglaterra onde a imprensa assume um viés partidário), aliados a um elevado grau de profissionalização do campo jornalístico. Os constrangimentos externos em geral são oriundos das pressões comerciais e não de natureza política ou partidária (com exceção, mais uma vez, do caso inglês). Nos Estados Unidos predomina largamente o jornalismo orientado para a informação, mas na Inglaterra essa orientação é mesclada com a tradição inglesa do jornalismo opinativo. A capacidade de regulação do Estado (baseada, como no modelo corporativista europeu, em regras do tipo legal-racional) é mínima nos Estados Unidos, porém evidente na Inglaterra e no Canadá pelo menos no que concerne ao sistema público de televisão que é insulado da esfera política. Em todo caso, o modelo liberal pode ser definido basicamente pela ampla predominância das leis do mercado e pela limitação da capacidade de intervenção e regulação por parte do Estado. Nos três países o sistema político gira em torno de um pluralismo moderado, com alta taxa de consenso em torno dos valores comuns (democracia representativa, economia de mercado etc.) e uma dinâmica bipartidária que produz governos majoritários e parlamentares no caso do Canadá e Inglaterra.

Tomando-se as características gerais dos três modelos resumidos nos parágrafos anteriores sugiro, por aproximação e a partir do confronto entre semelhanças e diferenças, enquadrar o caso brasileiro no modelo pluralista 
polarizado (mediterrâneo). Do ponto de vista do sistema político, que por economia de espaço não poderá ser examinado aqui, as similitudes são várias: um passado autoritário (que obviamente implicou na ausência, por longos períodos, da liberdade de imprensa), democratização relativamente recente, uma dinâmica de embates partidários polarizados nos pleitos presidenciais entre as forças de esquerda (1989, 1994 e 1998) ou centro-esquerda (2002) e centro-direita (de 1989 a 2002) configurando um nítido pluralismo polarizado, ainda que nos últimos anos de forma moderada ${ }^{1}$. A estas características políticas soma-se a existência de um Estado com um inequívoco passado autárquico, estatizante e intervencionista (inclusive na área de comunicação) e a introdução tardia de um padrão burocrático-racional na ação governamental e nos processos de governança.

A seguir, recorrendo a duas das quatro dimensões analíticas do modelo de Hallim e Mancini - mercado de mídia e paralelismo político - e adicionando a dimensão da diversidade externa, que considero importante para analisar o caso brasileiro, descrevo em linhas gerais as características do nosso sistema de mídia e discuto sua relação com o sistema político, focalizando, em especial, o comportamento do jornalismo político nos períodos políticos críticos que são os momentos eleitorais. Antes, advirto o leitor que uso indistintamente no texto as expressões "grande imprensa", "mídia de massa" e "sistema de mídia" para designar basicamente os meios de comunicação de massa com efetiva presença e influência nacional, como os jornais diários do eixo Rio-São Paulo, às vezes também denominados de "grandes jornais" (Folha de S. Paulo, O Estado de S. Paulo, O Globo e Jornal do Brasil), as revistas de informação semanal (Veja, Época, IstoÉ, Carta Capital) e as redes nacionais de televisão aberta (Globo, SBT, Record e Bandeirantes). Portanto, a mídia de alcance regional ou local, bem como as emissoras de rádios, não são objetos de consideração no presente texto.

\section{O mercado de mídia}

Exploro, agora, quatro características específicas, porém fundamentais, para descrever e analisar o mercado de mídia brasileiro de acordo com as indicações do modelo aqui adotado: surgimento tardio da imprensa, baixa circulação dos jornais, orientação para as elites e centralidade da televisão no sistema de mídia.

Uma breve revisão histórica desde períodos mais remotos deixa claro o surgimento tardio da indústria jornalística no país. A política colonial de Portugal procurava nos isolar do mundo através de políticas restritivas como o fechamento

\footnotetext{
${ }^{1}$ Sobre o conceito de pluralismo polarizado e moderado ver Sartori (1982, p. 156).
} 
dos nossos portos para o comércio internacional e a proibição de fábricas, escolas superiores e universidades e a impressão de livros e jornais em solo brasileiro. Por conta disso, o primeiro jornal, o Correio Braziliense, surgiu apenas em 1808, ano da transferência da Corte para o Brasil e da liberação das restrições impostas pela política colonial (LUSTOSA, 2003). Contudo, o Correio Braziliense era editado e distribuído a partir de Londres, e assim podemos considerar que o primeiro jornal efetivamente impresso no Brasil foi a Gazeta do Rio de Janeiro, também lançado em 1808, cuja pauta se limitava à publicação dos decretos da Corte e à cobertura das atividades da família real exilada no Brasil. A partir de 1821 surgem novos jornais, boa parte deles ligada aos liberais e à maçonaria, e após a Independência e ao Iongo do Império, a imprensa brasileira não só se ampliou como se diversificou com a publicação de dezenas de pequenas folhas, panfletos e pasquins, em geral de vida intermitente e breve. Somente na passagem do século XIX para o XX é que a imprensa brasileira começaria a ganhar uma estrutura empresarial que redefiniria a relação dos jornais com a política, os anunciantes e o leitor, e daria origem à chamada "grande imprensa" no eixo Rio-São Paulo (SODRÉ, 1999). Os grandes jornais de circulação nacional de hoje, como O Estado de S. Paulo e o Jornal do Brasil, foram criados nos anos finais do século XIX, sendo seguidos pelo extinto Correio de Manhã (1901) e pelos O Globo e a Folha de São Paulo (que nasceu com o nome de Folha da Manhã), ambos criados em 1925. Em suma, a imprensa escrita brasileira nasceu tardiamente e só ganhou uma estrutura comercial há apenas um século. Porém, a efetiva modernização industrial, comercial e gráfica dos jornais só iria ocorrer de fato a partir das décadas de 1960 e 1970 (ABREU, 2002), e só com o surgimento do rádio no início da década de 1920 e a sua rápida popularização na década seguinte que teríamos o início da era da comunicação de massa. Contudo, o processo de formação de um mercado de massa foi demorado e só se completaria com a chegada posterior da televisão, na década de 1950, e a criação e expansão das redes nacionais de rádio e televisão na década de 1970. Assim, somente a partir dos anos 1980 é que o nosso sistema de mídia ganharia uma feição inequívoca de uma indústria de massa, com a televisão ocupando um lugar central no mercado nacional de entretenimento e informação.

Em relação à baixa circulação dos jornais brasileiros, os dados são definitivos. Enquanto países como a Noruega vendiam, em 2000, 719,7 jornais por mil habitantes ${ }^{2}$, o Brasil, em 1994, vendia apenas 38,2 jornais (HALLIM e MANCINI, 2004 , p. 23; MATTOS, 2005, p. 142), refletindo a modestíssima circulação dos jornais brasileiros, que sequer alcança uma tiragem média anual de meio milhão de exemplares por veículos, conforme se pode ver na tabela a seguir:

\footnotetext{
2 Inglaterra - 408,5; Estados Unidos - 263,6; França - 190; Espanha - 129,4; e Portugal - 82,7.
} 
Tabela 1

Jornais com maior circulação - Brasil (2005)

\begin{tabular}{|c|c|}
\hline Jornais & Média anual (milhares) \\
\hline Folha de S. Paulo (SP) & 307,9 \\
\hline O Globo (RJ) & 274,9 \\
\hline Extra (RJ) & 271,8 \\
\hline O Estado de S. Paulo (SP) & 230,9 \\
\hline Zero Hora (RS) & 178,2 \\
\hline Correio do Povo (RS) & 167,7 \\
\hline Diário Gaúcho (RS) & 152,5 \\
\hline O Dia (RJ) & 152,3 \\
\hline Lance (RJ) & 116,4 \\
\hline Agora (SP) & 80,6 \\
\hline
\end{tabular}

Fonte: Balanço anual do IVC (Instituto Verificador de Circulação).

Obs.: 0 Jornal do Brasil teve circulação média de 68,2 (decréscimo de 10\% em relação a 2004).

Para simples efeito de comparação, a soma da circulação média anual dos cinco jornais relacionados na Tabela 1 não alcança a circulação média de um jornal como o New York Times, que roda todos os dias 1,6 milhões de exemplares. De fato, a grande barreira para a expansão da circulação dos jornais no Brasil é o baixo nível de escolarização. Segundo dados do IBGE, havia no país, em 2003, 11,6 \% de analfabetos e os indivíduos com mais de 10 anos de estudo não ultrapassavam 25\% da população. Esta situação reflete-se diretamente nos dados da tabela seguinte sobre os hábitos de leitura de jornais na região da Grande São Paulo, a mais rica e escolarizada do país.

Tabela 2

Evolução trimestral de hábitos de leitura - Grande São Paulo (2005)

\begin{tabular}{|c|c|}
\hline Período & $\begin{array}{c}\text { Indivíduos que lêem } \\
\text { habitualmente (\%) }\end{array}$ \\
\hline janeiro/2005 a março/2005 & 36,1 \\
\hline fevereiro/2005 a abril/2005 & 35,5 \\
\hline março/2005 a maio/2005 & 33,7 \\
\hline abril/2005 a junho/2005 & 32,0 \\
\hline maio/2005 a julho/2005 & 32,5 \\
\hline junho/2005 a agosto/2005 & 34,2 \\
\hline julho/2005 a setembro/2005 & 35,1 \\
\hline agosto/2005 a outubro/2005 & 35,0 \\
\hline setembro/2005 a novembro/2005 & 35,9 \\
\hline
\end{tabular}

Fonte: IBOPE - Monitor Plus 
Além da baixa circulação e penetração dos jornais - e entro agora no terceiro ponto e na questão da orientação dos jornais para a elite - a grande imprensa nacional possui como target os estratos sócio-econômicos A e B (ver Tabela 3), enquanto que os estratos $C, D$ e $E$ são cobertos pelos chamados jornais populares, todos eles de circulação estritamente local.

Tabela 3

Índice de leitura de jornais por classe sócio-econômica - Brasil (2000)

\begin{tabular}{|c|c|}
\hline Classe sócio-econômica & Índice de leitura diária \\
\hline AB & 180 \\
\hline C & 89 \\
\hline DE & 38 \\
\hline
\end{tabular}

Fonte: TGI Brasil (Target Group Index)

Obs: $\mathbf{1 0 0}$ = População em geral. Um índice maior que 100 significa que as pessoas de uma classe são mais propensas a ler jornais diários do que a população em geral e menor do que 100 que são menos.

Com uma circulação dirigida para os leitores das classes AB (os chamados "formadores de opinião"), os grandes jornais, além da linguagem sóbria e culta, priorizam a cobertura política e econômica e praticam um jornalismo opinativo que coexiste com a tendência mais recente de se fazer um jornalismo de informação. Orientados para a elite e os formadores de opinião, estes jornais compensam a baixa penetração nas camadas populares com a grande capacidade de produzir agendas, formatar questões e influenciar percepções e comportamentos tanto no âmbito político-governamental quanto no público em geral, este último através dos líderes de opinião ou através da repercussão da pauta dos jornais na televisão aberta.

Finalmente, o quarto ponto analisado é a centralidade da televisão no mercado de mídia e de informação. Esta centralidade pode ser medida por dois indicadores, além da clássica e óbvia medição da audiência: a participação do setor televisivo no volume dos investimentos publicitários e a presença de aparelhos de televisão nos domicílios. Os dados sobre a distribuição da verba publicitária total investida em 2005 no Brasil não deixam dúvidas sobre o peso e a importância que a televisão, tanto aberta quanto por assinatura, em especial as emissoras ligadas à Rede Globo, possuem no mercado de mídia e no mercado publicitário. 
Tabela 4

Investimento publicitário por setor - Brasil (2005)

\begin{tabular}{|l|c|}
\hline Setor & Participação (\%) \\
\hline TV aberta & $59,6\left(^{*}\right)$ \\
\hline Jornal & 16,3 \\
\hline Revista & 8,8 \\
\hline TV a cabo & 2,3 \\
\hline Rádio & 4,2 \\
\hline Mídia exterior & 4,3 \\
\hline Internet & 1,7 \\
\hline Outros & 12,8 \\
\hline Total & 100 \\
\hline
\end{tabular}

Fonte: Inter-meios/PricewaterhouseCoopers

(*) Dos quais aproximadamente $76 \%$ alocados na TV Globo

Porém, certamente o indicador mais direto e acurado sobre a centralidade da televisão no mercado de informação e entretenimento é o número de aparelhos de televisão em domicílios familiares aferido pelo IBGE (Tabela 5). Este indicador, para efeito da análise aqui desenvolvida, deve ser confrontado com os números já apresentados sobre a circulação e os hábitos de leitura dos jornais. Como mostram as Tabelas 2 e 5, enquanto praticamente $2 / 3$ da população não lêem jornais habitualmente, $90 \%$ dos domicílios permanentes no Brasil possuem aparelho de televisão e $88 \%$ possuem aparelho de rádio.

Tabela 5

Aparelhos de mídia eletrônica e domicílios por grandes regiões - Brasil (2004)

\begin{tabular}{|c|c|c|c|c|c|c|}
\hline \multirow{3}{*}{ Aparelhos } & \multicolumn{6}{|c|}{ Domicílios particulares permanentes (N/\%) } \\
\hline & \multirow{2}{*}{ Brasil } & \multicolumn{5}{|c|}{ Grandes Regiões } \\
\hline & & Norte & Nordeste & Sudeste & Sul & Centro-Oeste \\
\hline Total & 51752528 & 3561524 & 13090124 & 23157114 & 8198266 & 3745500 \\
\hline Rádio & $\begin{array}{c}45430369 \\
(88 \%)\end{array}$ & $\begin{array}{c}2599403 \\
(73 \%)\end{array}$ & $\begin{array}{c}10558203 \\
(81 \%)\end{array}$ & $\begin{array}{c}21417655 \\
(92 \%)\end{array}$ & $\begin{array}{c}7671114 \\
(94 \%)\end{array}$ & $\begin{array}{c}3183994 \\
(85 \%)\end{array}$ \\
\hline Televisão & $\begin{array}{c}46733120 \\
(90 \%)\end{array}$ & $\begin{array}{c}2825587 \\
(79 \%)\end{array}$ & $\begin{array}{c}10692259 \\
(82 \%)\end{array}$ & $\begin{array}{c}22154629 \\
(96 \%)\end{array}$ & $\begin{array}{c}7693795 \\
(94 \%)\end{array}$ & $\begin{array}{c}3366850 \\
(90 \%)\end{array}$ \\
\hline Computador & $\begin{array}{c}8458311 \\
(16 \%)\end{array}$ & $\begin{array}{c}244234 \\
(7 \%)\end{array}$ & $\begin{array}{c}891918 \\
(7 \%)\end{array}$ & $\begin{array}{c}5098113 \\
(22 \%)\end{array}$ & $\begin{array}{c}1665204 \\
(20 \%)\end{array}$ & $\begin{array}{c}558842 \\
(15 \%)\end{array}$ \\
\hline $\begin{array}{l}\text { Acesso à } \\
\text { Internet }\end{array}$ & $\begin{array}{c}6324420 \\
(12 \%)\end{array}$ & $\begin{array}{c}149020 \\
(4 \%)\end{array}$ & $\begin{array}{c}642811 \\
(5 \%)\end{array}$ & $\begin{array}{c}3885377 \\
(17 \%)\end{array}$ & $\begin{array}{c}1229623 \\
(15 \%)\end{array}$ & $\begin{array}{c}417589 \\
(11 \%)\end{array}$ \\
\hline
\end{tabular}

Fonte: IBGE - PNAD 
Os dados cruzados das Tabelas 2 e 5 traduzem em números atualizados o que todos nós já sabemos há muito, ou seja, que o principal acesso dos brasileiros ao sistema de mídia se dá através da mídia eletrônica, o rádio e a televisão, indicando que pelo menos $2 / 3$ da população obtêm suas informações básicas sobre o país e o mundo através destes dois veículos. Porém, os assuntos políticos não constituem um dos interesses prioritários dos espectadores, conforme se pode constatar na Tabela 6. Apesar disso, diversas pesquisas mostram que nos períodos eleitorais as principais fontes de informação do eleitor são justamente os programas do Horário Gratuito de Propaganda Eleitoral (HGPE) e que os debates eleitorais travados nos pleitos majoritários mais competitivos (como as disputas presidenciais) atraem a atenção de milhões de espectadores e eleitores.

Tabela 6

Tipos de programas de TV mais assistidos - Pesquisa amostral - Brasil (2003)

\begin{tabular}{|l|c|}
\hline Programas & $\begin{array}{c}\text { entre os } \\
\text { respondentes (\%) }\end{array}$ \\
\hline 1. Notícias nacionais & 70 \\
\hline 2. Notícias locais & 69 \\
\hline 3. Notícias internacionais & 55 \\
\hline 4. Ação/Aventura & 54 \\
\hline 5. Comédia & 52 \\
\hline 6. Novelas & 49 \\
\hline 35. Política & 15 \\
\hline
\end{tabular}

Fonte: TGI Brasil (Target Group Index).

$\mathrm{N}$ : 5.312 informantes.

\section{A diversidade externa}

A diversidade externa, definida aqui como a existência efetiva de diversidade de informação e de opinião nos meios de comunicação de massa de forma a garantir que garanta aos cidadãos acesso às principais perspectivas políticas em competição, é uma dimensão extremamente crítica na articulação entre o sistema de mídia e o sistema político das democracias contemporâneas. Como lembra muito bem Maia (2002, p. 5), tanto os autores vinculados à perspectiva pluralista, como Dahl (1971), quanto os filiados à corrente deliberacionista, como Habermas (1984) e Fraser (1992), consideram que a diversidade de fontes de informação e a pluralidade de opiniões são cruciais para a efetividade do debate das questões públicas e das decisões políticas nas poliarquias ou para a deliberação crítica e 
racional no âmbito da esfera pública. Seja como for, para assegurar as condições democráticas referidas é imprescindível que os meios de comunicação de massa estejam organizados numa estrutura plural e competitiva e seja capaz de refletir, se não toda, pelo menos as correntes mais importantes da diversidade ideológica, política e cultural da sociedade. Esta configuração ideal do campo jornalístico é mais fácil de ser encontrada num sistema de mídia no qual predomine ou coexista com a imprensa comercial uma imprensa partidária (ou comprometida com causas sociais não-hegemônicas), como ocorre nos países escandinavos e no caso inglês, em que os jornais ainda são muitos ligados aos partidos políticos. Num contexto onde a imprensa comercial é dominante, seja pela inexistência ou pela pequena expressão da imprensa partidária, o princípio democrático da diversidade e pluralidade estaria inevitavelmente dependente do ideal normativo da objetividade tão cara à perspectiva teórica do jornalismo liberal, ou seja, dependente da presença de uma diversidade interna em cada órgão de imprensa que permita o confronto de opiniões divergentes e coberturas balanceadas em que todos os lados e atores em disputa sejam contemplados.

Além disso, é necessário também lembrar o papel estratégico da mídia de massa na visibilidade das questões públicas nas democracias contemporâneas. Estas democracias funcionam em sociedades complexas, socialmente diferenciadas e fortemente segmentadas em seus interesses políticos e culturais por clivagens de classe, gênero, etnia, geração etc. Nesse contexto, como é o caso brasileiro, diversos temas e questões competem entre si para obter atenção da opinião pública e só se transformam verdadeiramente em questões públicas quando ganham visibilidade nos meios de comunicação de massa. Há, assim, na arena midiática, uma disputa incessante entre as várias agendas postas em circulação por diversos atores sociais e políticos, inclusive a própria imprensa que, em momentos excepcionais (como no impeachment dos presidentes Nixon e Collor), pode vir a assumir a posição de ator principal do processo político. Portanto, a visibilidade/invisibilidade dos atores, temas e demandas dependem em larga medida, no regime democrático, do grau de pluralidade externa existente no sistema de mídia ou da pluralidade interna praticada em cada jornal, revista ou emissora de TV e rádio.

Além da diversidade externa, que é basicamente a pluralidade na oferta de informações e opiniões, a questão da visibilidade/invisibilidade pode ser pensada também pelo ângulo do acesso dos grupos sociais à mídia e da capacidade destes grupos influenciá-la. Fraser (1992), analisando a desigualdade comunicativa no caso das relações de gênero, criou as categorias de "públicos fortes" e "públicos fracos" para diferenciar analiticamente os sujeitos ativos e passivos no processo de formação da opinião pública. Resumidamente, o público forte é constituído pelos grupos que possuem recursos políticos, simbólicos ou econômicos suficientemente 
fortes para produzir agendas e tomada de decisão e influenciar a opinião pública. 0 público fraco, embora participe da formação da opinião pública, obviamente não possui recursos suficientes para configurála de acordo com seus interesses políticos e sociais, nem detém poder de decisão nas esferas políticas e econômicas. O conceito de Fraser é operacionalmente interessante porque permite identificar os atores com acesso aos meios de comunicação e avaliar a capacidade deles proporem agendas para a mídia e, através dela, para o público. Embora os estudos empíricos sobre a agenda da mídia ainda engatinhem no Brasil (AZEVEDO, 2004a), é razoável sustentar a hipótese de que em nosso sistema de mídia a baixa diversidade externa está constitutivamente associada à relação histórica da mídia com as elites, especialmente dos grandes jornais, o que potencializa a capacidade dos vários segmentos do público forte de agendar temas e questões na imprensa e, através dela, na opinião pública. Feita essas considerações gerais e preliminares, passo agora para o exame do caso brasileiro.

Segundo Lima (2001, p. 104), as constituições brasileiras desde 1946 proibiam o controle das empresas jornalísticas e de radiodifusão por parte de pessoas jurídicas, sociedades anônimas por ações e estrangeiros. A intenção dos legisladores, conforme esclarece o autor, era permitir a identificação plena dos proprietários e impedir o controle da mídia pelo capital estrangeiro. Contudo, o efeito indireto de tais restrições legais produziu a formação de monopólios familiares no setor das comunicações de massas. Ainda conforme Lima, apenas oito grupos familiares controlam o setor de rádio e televisão no Brasil, conforme se pode ver na tabela que se segue:

Tabela 7

Grupos familiares e números de emissoras na radiodifusão brasileira

\begin{tabular}{|l|c|c|}
\hline Nacionais & Televisão & Rádio \\
\hline Marinho (Globo) & 32 & 20 \\
\hline Saad (Bandeirantes) & 12 & 21 \\
\hline Abravanel (SBT) & 10 & - \\
\hline Regionais & Televisão & Rádio \\
\hline Sirotsky (RBS-Sul) & 20 & 20 \\
\hline Câmara (Centro-Oeste) & 08 & 13 \\
\hline Daou (Norte) & 05 & 04 \\
\hline Zahran (Mato-Grosso) & 04 & 02 \\
\hline Jereissati (Nordeste) & 01 & 05 \\
\hline
\end{tabular}

Fonte: LIMA (2001, p. 106).

Obs.: Embora a legislação em vigor limite a cinco o número de emissoras de TV por grupo, as redes nacionais burlam a regra se associando às estações de outros proprietários que funcionam como meras repetidoras locais ou regionais da programação nacional. 
Além dessas oito famílias, que atuam também na mídia impressa e eletrônica (internet), outros três outros grupos familiares controlam várias ramificações importantes do sistema de mídia brasileiro que englobam parques gráficos, jornais, revistas, portais e sites e TV por assinatura: os Civitas (grupo Abril), os Mesquitas (grupo O Estado de S. Paulo) e os Frias (grupo Folha de S. Paulo). Desta forma, 90\% da mídia brasileira é controlada por apenas 15 grupos familiares (LIMA, 2001, p. 106).

Além do monopólio familiar, outra característica marcante do sistema de mídia brasileiro é o controle de parte importante das emissoras de rádio e televisão por políticos. Até 1988, ano da promulgação da atual Constituição, a concessão de serviços de radiodifusão era prerrogativa exclusiva do Presidente da República que naturalmente usava este privilégio como moeda de troca política. Como resultado desta legislação permissiva criou-se no Brasil uma espécie de "coronelismo eletrônico", com políticos controlando e usando a mídia local ou regional para seus interesses políticos e eleitorais. Como lembra Lima (2001, p. 108), um levantamento de 1990 mostrava que 50\% das emissoras de rádio da Bahia eram controlados por políticos, 44\% em Pernambuco, 33\% em Minas Gerais e 20\% em São Paulo. A tabela a seguir resume a situação no panorama nacional.

Tabela 8

Emissoras de rádio e televisão controladas por políticos - Brasil (1994)

\begin{tabular}{|l|c|c|c|}
\hline Emissoras & Total Brasil & Políticos e ex-políticos & $\%$ \\
\hline Televisão & 302 & 94 & 31,12 \\
\hline Rádio & 2.908 & 1.169 & 40,19 \\
\hline
\end{tabular}

Fonte: LIMA (2001, p. 107).

De acordo com o autor, mesmo com as novas regras definidas pela Constituição de 1988 a prática de distribuir as concessões dos serviços de radiodifusão continuaram: das 1.848 estações repetidoras de TVs autorizadas depois de 1995, já no governo de Fernando Henrique Cardoso 268 foram dadas a empresas ou entidades controladas por políticos (LIMA, 2001, p. 109).

As novas regras adotadas nos últimos anos, sob pressão do processo de globalização e da onda neoliberal de desregulamentação, quebraram o monopólio estatal das telecomunicações e permitiram a participação estrangeira, embora minoritária, nos meios de comunicação de massa do país. Contudo, os efeitos de tais alterações legais ainda não resultaram em mudanças relativas ao controle dos 
principais meios de comunicação de massa brasileiros. Ao contrário, o monopólio familiar não só sobreviveu como se fortalece através da política de aquisições e fusões que configura um aprofundamento da propriedade cruzada nos meios de comunicação de massa. O grupo Abril, controlado pela família Civita, continua a liderar o mercado de revistas ao mesmo tempo em que opera uma das principais redes de TV a cabo do país (TVA) e uma emissora de sinal aberto (MTV); a família Marinho, através das Organizações Globo produz jornais (inclusive O Globo, um dos líderes de circulação nacional), revistas, livros, discos, filmes e lidera amplamente o mercado de TV aberta e de assinatura (NET); e as famílias Frias e Mesquita, que editam dois dos principais jornais de circulação nacional (respectivamente a Folha de S. Paulo e O Estado de S. Paulo), expandiram em anos recentes seus negócios para os novos meios eletrônicos, como a internet.

Em resumo, o monopólio familiar, a propriedade cruzada dos principais meios de comunicação de massa, o controle parcial de redes locais e regionais de TV e rádio por políticos profissionais, e a inexistência de uma imprensa partidária ligada a interesses sociais minoritários com alguma expressão nacional faz com que nosso sistema de mídia apresente ainda, depois de mais de duas décadas do retorno à democracia, uma reduzida e precária diversidade externa. Este quadro adverso na oferta de fontes diversificadas de informação e opinião converte automaticamente a questão da diversidade interna num dos pontos cruciais no exame da articulação entre o nosso sistema de mídia e o sistema político, o qual abordo no próximo item.

\section{O paralelismo político}

Para Hallim e Mancini (2004, p. 21) o paralelismo político é definido de modo mais estrito pela natureza e grau da relação mantida entre os meios de comunicação de massa e os partidos e organizações políticas. Ou, de um modo mais geral, pela forma e extensão pela qual o sistema de mídia reflete as divisões políticas existentes no interior da sociedade. Os autores, numa breve revisão histórica, lembram que, na Europa, o jornalismo nasceu e se desenvolveu desempenhando um papel importante na defesa de causas políticas e religiosas. Em muitos casos e em vários países, os jornais eram fundados sob a iniciativa de partidos políticos ou outros atores políticos ou simplesmente apoiavam idéias políticas e promoviam partidos e candidatos. Em sua origem, portanto, o jornalismo apresentava um forte paralelismo político. No final do século XIX, quando a imprensa comercial começou a se estruturar de modo mais sistemático, o jornalista passou a ser normativamente construído como um "árbitro neutro", distanciado de causas coletivas e interesses pessoais e sem coloração política ou partidária. Deste 
modo, o ideal liberal e normativo da objetividade e da neutralidade jornalística está fortemente articulado com a passagem do jornalismo partidário para o jornalismo comercial e com o surgimento do jornalista profissional e das normas deontológicas da profissão.

Contudo, é um erro contrapor de forma dicotômica uma imprensa comercial supostamente objetiva e neutra a uma imprensa política com viés político e partidário (HALLIM e MANCINI, 2004, p. 26). Primeiro, porque nenhum analista sério seria capaz de defender a idéia de que objetividade e neutralidade existem de fato em algum jornal do mundo, pois um grande número de pesquisas mostra que os jornalistas compartilham crenças ideológicas como qualquer outro indivíduo e que os padrões de recrutamento profissional e as rotinas produtivas nas redações incorporam consciente ou inconscientemente valores culturais e políticos. Segundo, porque jornais comerciais freqüentemente assumem posições políticas e até mesmo partidárias (especialmente nos momentos eleitorais), enquanto que jornais partidários podem adotar, e muitos adotam, normas de equilíbrio e balanceamento em suas reportagens. Além do mais, deve-se levar também em conta que no jornalismo comercial moderno a diferenciação política dos jornais se dá muito mais pelas crenças políticas e valores morais do que pela associação com uma organização partidária ou política em particular. Nestes termos, o Financial Times, por exemplo, deve ser visto como uma revista de forte orientação conservadora, mas não necessariamente como um house organ do Partido Conservador; da mesma forma, o New York Times no contexto americano é um jornal liberal, mas não deve ser confundido como porta-voz do Partido Democrata.

Por fim, é importante lembrar que a noção de paralelismo político está fortemente articulada aos conceitos de diversidade externa e interna, pois ele se refere basicamente à propensão de cada sistema de mídia em refletir de forma equilibrada ou desbalanceada a diversidade das orientações políticas existentes na sociedade. Entre os vários indicadores apontados por Hallim e Mancini para caracterizar o grau de paralelismo político estão: as conexões entre a imprensa e as organizações políticas (partidos, sindicatos, associações, igrejas etc.); a intervenção da mídia na vida política, especialmente nos períodos eleitorais; a visibilidade de militantes e políticos nos programas de audiência no rádio e TV e nos jornais; o predomínio de comentários e análises visando influenciar a opinião pública em detrimento de informações balanceadas etc. Porém, segundo os autores, o indicador mais básico talvez seja o conteúdo veiculado pela mídia, o volume que os meios de comunicação de massa concedem aos temas e questões políticas e as formas de enquadramento adotadas para abordá-los. Como veremos mais adiante esse indicador tem sido freqüentemente usado entre nós para monitorar e analisar o comportamento da mídia nos períodos eleitorais. Porém, com as exceções de praxe, estas aferições não incorporam uma análise referenciada teoricamente ou 
são empiricamente restritas a episódios eleitorais isolados. Faço, a seguir, uma súmula histórica da atuação da mídia em três períodos políticos distintos, especialmente nos processos eleitorais, e discuto a natureza e o grau de paralelismo político do nosso sistema de mídia.

A mídia brasileira até a década de 1960, restrita à imprensa escrita e ao rádio (a TV só se tornaria relevante nos anos 1970) no qual se destacavam os veículos ligados ao grupo Diários Associados, era extremamente frágil do ponto de vista comercial e dependente dos favores públicos. Com o país vivendo ainda um incipiente processo de industrialização e o mercado publicitário engatinhando, o faturamento dos veículos dependia basicamente dos classificados populares e dos anúncios de varejo do comércio, e dependia ainda dos financiamentos dos bancos públicos, subsídios para a compra de papel, isenções fiscais e da propaganda oficial (ABREU, 2002, p. 9).

Paradoxalmente, apesar desta fragilidade econômica e financeira, como lembra Abreu (2002, p. 12), a grande imprensa brasileira nas décadas de 1950 e 1960 tinha um alto nível de envolvimento e participação nas lutas políticas da época, marcada pela disputa entre varguistas e anti-varguistas e, do ponto de vista partidário e a partir de 1946, entre o PSD e a UDN. Em São Paulo, O Estado de S. Paulo, da família Mesquita, cerrava fileiras contra Vargas desde os anos 1930 . No Rio de Janeiro, a Tribuna da Imprensa, ligada a Carlos Lacerda, e O Globo, da família Marinho, também faziam oposição a Vargas e apoiavam a UDN, enquanto que o hoje extinto Última Hora, fundado por Samuel Wainer, endossava Vargas e seu governo. Com o suicídio do presidente Vargas em 1954, o Última Hora apoiaria políticas nacionalistas e reformistas e, no final do período democrático de 1946-64, o governo Goulart. Todos os jornais citados, aos quais se deve ainda somar o Jornal do Brasil e o hoje extinto, mas então importante Correio da Manhã, e com a exceção evidentemente do Última Hora, podem ser definidos como órgãos conservadores, ideologicamente liberais tanto do ponto de vista do ideário econômico quanto das crenças políticas. Contudo, como se sabe, os auto-proclamados princípios do liberalismo político não impediram que estes jornais participassem ativamente do movimento pela deposição do governo Goulart e apoiassem a instalação do governo militar em 1964. O balanço do período populista (1946-1964) mostra, portanto, que a nossa grande imprensa apresentou um alto nível de paralelismo político, seja na defesa de valores ideológicos (liberalismo versus nacionalismo e estatismo ou socialismo), seja no engajamento partidário (UDN versus PSD.PTB) e político (antivarguismo, antipopulismo, deposição de Goulart).

O período seguinte (1964-1985), marcado pelo regime militar e pela rígida censura à imprensa, obviamente mostra uma baixa atividade política dos meios de comunicação de massa. O paralelismo político, quando ocorre, se dá em oposição ao regime militar, e não em torno de interesses partidários ou conflitos ideológicos. 
De um ponto de vista mais geral, este período foi caracterizado por uma forte expansão do sistema de mídia, pela ascensão da televisão como principal veículo de massa, pela modernização e concentração dos jornais diários e pela grande expansão e segmentação do setor de revistas. A criação da Embratel em 1965 e a implantação da rede de telecomunicações e de estações repetidoras pelo país afora nos anos seguintes expandiram nacionalmente as redes de televisão, até então de alcance meramente local ou regional, e transformou rapidamente a Rede Globo na principal rede nacional. Ao mesmo tempo, no campo do jornalismo diário, houve um acelerado processo de modernização industrial e das rotinas produtivas e uma forte concentração da propriedade com a extinção de vários títulos tradicionais como o Correio da Manhã e o Última Hora. No setor das revistas ocorreu processo semelhante com a liquidação de títulos tradicionais das décadas de 1950 e 1960 como O Cruzeiro, Manchete e Fatos e Fotos, e o surgimento de novas revistas com novos formatos, como as revistas de informação e reportagem, Veja e Realidade, esta última também extinta anos depois. Paralelo a todo esse movimento, realizouse também um rápido processo de profissionalização do jornalista, com a disseminação de cursos superiores de jornalismo e a regulamentação da profissão. Contudo, do ponto de vista político, a grande novidade foi o surgimento de uma imprensa alternativa anárquica e de esquerda, editado em formato de tablóide e em oposição aberta ao regime e à censura, que sobreviveria financiada apenas com assinaturas e vendas em banca até o início da década de 1990, como os jornais 0 Pasquim, Opinião, Movimento, entre outros.

Neste contexto autoritário e diante de um ambiente político rarefeito e marcado por um bipartidarismo compulsório e pela ausência de competição e alternância política real, apesar da censura prévia imposta pelos militares, a grande imprensa escrita evoluiu de um apoio entusiasmado à implantação do regime militar para uma oposição liberal e moderada, porém crescente, ao regime militar. O primeiro jornal a trilhar nesse caminho foi o extinto Correio da Manhã, seguido pelos Jornal do Brasil, Folha de S. Paulo e O Estado de S. Paulo. Mas, esta posição mais crítica ficou confinada à imprensa escrita, pois o governo manteve durante todo o período mais duro do regime militar uma rígida censura, que se somava a autocensura e ao apoio espontâneo ao governo (caso da Rede Globo), aos meios de comunicação eletrônicos. Com a posse de Geisel em 1974 e o início da abertura política que conduziria à revogação dos atos institucionais e a Lei de Anistia, em 1979, bem como ao retorno do multipartidarismo e as eleições diretas para os governos estaduais, em 1982, a grande imprensa ampliou paulatinamente seus limites de liberdade e sua capacidade de propor agenda de debates e refletir a opinião pública. Sem dúvida, o ponto alto deste processo foi a campanha das Diretas Já, em 1983 e 1984, que teve na Folha de S. Paulo um dos seus principais arautos, enquanto a Rede Globo escondia do público as grandes manifestações 
populares e ignorava o debate nacional pelas eleições diretas para Presidência da República.

O retorno à democracia em 1985 recolocou o sistema de mídia novamente vis-à-vis o sistema político e os embates partidários. Embora o nosso sistema de mídia tenha mantido suas características gerais ao longo do tempo - monopólio familiar, propriedades cruzadas nos meios de comunicação de massa e reduzida diversidade externa - algumas mudanças importantes devem ser anotadas para se entender o comportamento da mídia diante dos processos políticos e eleitorais neste atual período democrático.

Em relação à mídia eletrônica, além da forte expansão das redes nacionais de televisão aberta pelo país adentro e da chegada da televisão por assinatura, e mais recentemente da internet, a principal novidade em relação ao período anterior e do ponto de vista do seu impacto político foi o aperfeiçoamento da legislação eleitoral que regulamenta o uso do rádio e da televisão antes e durante os períodos eleitorais. Com efeito, a lei 9.504 de 30/09/1997 criou, em seus artigos 45 e 46, regras e normas rígidas que regulamentam fortemente a programação e o noticiário das rádios e televisões três meses antes dos eventos eleitorais, impedindo assim qualquer tentativa destes veículos apoiarem ou beneficiarem direta ou indiretamente partidos e candidatos. Esta legislação, associada ao Horário Gratuito de Propaganda Eleitoral (HGPE), transformou pela via do constrangimento institucional os meios eletrônicos nos veículos mais democráticos do nosso sistema de mídia durante os períodos eleitorais. Pode parecer pouco, mas isto representa um avanço extremamente significativo do ponto de vista da igualdade comunicativa e política, especialmente quando consideramos o potencial que a televisão tem de influenciar a opinião pública, ainda mais no nosso contexto em que a Rede Globo praticamente detém o monopólio da audiência nacional.

Sobre a mídia impressa, deve-se lembrar inicialmente que os jornais diários passaram nas décadas de 1970 e 1980 por um grande processo de modernização industrial, gráfico e editorial, incorporando em suas rotinas produtivas técnicas jornalísticas padronizadas (em geral resumidas por manuais de redação) e adotando uma política de recrutamento profissional. Estas mudanças foram acompanhadas por políticas comerciais e de marketing agressivas que transformaram conceitualmente os jornais em prestadores de serviços e os antigos leitores em consumidores. Todas estas transformações foram realizadas sob a pressão de uma acirrada competição comercial entre os principais jornais de circulação nacional a qual engendrou uma nova visão de negócios em que a informação e a credibilidade se transformaram, pelo menos teoricamente, nas principais mercadorias dos jornais, implicando, por sua vez, na valorização do jornalismo informativo em detrimento do jornalismo opinativo, muito embora este sobreviva entre nós tanto nos jornais, através dos editorais, colunas assinadas e 
artigos, quanto nas revistas de informação semanal. Esta nova configuração editorial mais orientada para o jornalismo informativo vem fortalecendo a diversidade interna nos grandes jornais, o que significa uma maior abertura às perspectivas conflitantes sobre temas e questões em disputa pelos principais atores políticos e sociais e uma cobertura eleitoral mais equilibrada, como mostram diversos rastreamentos do comportamento da mídia realizados nos últimos anos por grupos acadêmicos (DOXA/IUPERJ, ECA/USP), crítica da mídia (Observatório da Imprensa) e pelos partidos políticos.

O primeiro evento político crítico para o sistema de mídia em nosso atual período democrático foi sem dúvida a eleição presidencial de 1989 (AZEVEDO e RUBIM, 1998). Apesar de disputada logo depois da queda dos regimes socialistas do Leste Europeu, o embate foi travado desde o início através de uma forte polarização ideológica entre a esquerda (através das candidaturas de Brizola e Lula) e a direita (Collor). De acordo com a literatura que pesquisou o comportamento da mídia no período (ver, entre outros, LIMA, 1990; ALBUQUERQUE, 1994; SOARES, 1997; GUIMARÃES e VIEIRA, 1989; RUBIM, 1995; AGUIAR, 1995), a cobertura da grande imprensa foi abertamente favorável, tanto na mídia impressa quanto na mídia eletrônica, a Collor, que era desde o início da competição o candidato que reunia melhores chances eleitorais de derrotar a esquerda. Ainda segundo alguns dos autores aqui citados, os principais jornais e revistas de circulação nacional defendiam em suas páginas opinativas as teses neoliberais, então hegemônicas na Inglaterra e nos Estados Unidos e atacavam às concepções estatais e nacionalistas, bem como os projetos socialistas. Segundo os pesquisadores aqui referidos, estas posições, anunciadas de modo aberto e direto nos editoriais e na maioria das colunas e artigos assinados, contaminou a cobertura eleitoral e comprometeu o equilíbrio em relação aos dois principais candidatos. Nos telejornais, embora o noticiário fosse mais equilibrado em termos de volume de tempo e atenção às candidaturas mais competitivas eleitoralmente, os enquadramentos foram freqüentemente favoráveis a Collor, como bem exemplificou a célebre edição da Rede Globo do debate final entre Collor e Lula na véspera do $2^{\circ}$ turno. Em resumo, o paralelismo político nesse período se expressou não só pela defesa aberta de valores políticos e idéias econômicas como também pelo engajamento eleitoral de praticamente toda a grande mídia nacional. É claro que boa parte desse comportamento partidarizado pode e deve ser atribuída ao clima de forte polarização ideológica e histeria política diante da possibilidade uma vitória da esquerda, um pesadelo real para uma imprensa historicamente conservadora. Seja como for, o apoio ao candidato conservador expresso pelos editoriais e artigos e a cobertura eleitoral desbalanceada indicavam de modo expressivo que nosso sistema de mídia entrava na democracia recém restaurada com um importante déficit democrático no que se refere à igualdade comunicativa. 
Entre as eleições de 1989 e a de 1994, que inaugura um novo tipo de polarização eleitoral, agora entre o PT e o PSDB, ambos com origem à esquerda, a imprensa assumiu um papel protagonista no episódio do impeachment do Collor. Sem dúvida, a crise do governo Collor foi um divisor de águas para a mídia (em especial para o jornalismo político), do ponto de vista da sua relação com o sistema político no novo período democrático, pois a grande imprensa durante todo o episódio não só agendou o debate político, como se transformou num dos principais atores da crise, denunciando o governo, mobilizando a opinião pública e colocando em pauta o impeachment. Nessa dinâmica marcada basicamente pelo jornalismo investigativo, a mídia brasileira mimetizou a função clássica do cão-de-guarda (watchdog) da teoria liberal do jornalismo assumindo o papel de vigia e fiscalizador do sistema político.

Com o lançamento do Plano Real durante o governo Itamar Franco (1992. 94), a grande imprensa apoiou entusiasticamente as medidas econômicas de estabilização monetária. Este apoio, que se manteria pelo final do governo Itamar e se prolongaria pelo mandato de Fernando Henrique Cardoso, estava em consonância com o forte apoio popular ao Plano Real. O apoio da imprensa logo se converteria numa adesão eleitoral aberta ou sutil, em 1994, à candidatura de FHC. Contudo, esta adesão não se deu mais em um quadro de aguda polarização ideológica e de histeria política como ocorreu em 1989. Agora, com dois candidatos oriundos do campo da esquerda, mas em coligações diferenciadas, o confronto se deu basicamente em torno do debate sobre o plano de estabilização monetária (a necessidade de preservá-lo versus a idéia de que era um engodo eleitoral como tinha sido o Plano Cruzado) e o conteúdo dos projetos de governo, que novamente contrapunham concepções estatizantes e nacionalistas às reformas liberais. Estes mesmos temas, mais a crise financeira internacional que eclodiu em vários países emergentes, estariam também presentes nas eleições de 1998, a primeira em que fora permitida a reeleição do presidente. E, da mesma forma, mas agora com o inevitável aumento da visibilidade do presidente-candidato/candidato-presidente na mídia por conta do manejo da crise financeira daquele momento (ver AZEVEDO, 2000, p. 54), a grande imprensa renovou o apoio eleitoral a FHC através dos editoriais e artigos. Apesar disto, um balanço confrontando a cobertura eleitoral de 1989 com 1994 e 1998 (CHAIA, 2004; MIGUEL, 1999; JORGE, 1997) mostra mudanças significativas no que se refere aos grandes jornais. Apesar das preferências políticas, a cobertura eleitoral a partir de 1994 passou a apresentar um maior equilíbrio entre as notícias dedicadas aos principais candidatos nas páginas informativas. Isto indica que, embora a diversidade externa continue a ser um problema crítico em nosso sistema de mídia, a diversidade interna passou a ser uma política editorial deliberada nos principais jornais do país, embora o mesmo não se possa afirmar em relação às revistas de informação semanal. Mas, de fato, 
revistas são um gênero de publicação essencialmente opinativo. Quanto à televisão, ao contrário dos jornais, mostrou grandes diferenças de comportamento no jornalismo televiso entre a campanha de 1994 e 1998. Na campanha de 1994, a televisão investiu pesadamente na realização de debates entre os candidatos e em uma cobertura jornalística intensa que proporcionou alta visibilidade aos dois candidatos principais e, por imposição legal, uma presença equilibrada nas edições dos telejornais. Porém, em 1998, com a televisão regulada pela lei 9.504 de 30/09/1997, a eleição presidencial se tornou praticamente invisível na televisão, pois a Rede Globo simplesmente ignorou a campanha eleitoral em seu jornalismo e não foi realizado um debate sequer entre os candidatos em nenhuma das redes nacionais. Obviamente, é ocioso comentar que esta invisibilidade das eleições favoreceu o candidato à reeleição e o favorito das pesquisas.

As tendências observadas nos pleitos anteriores foram aprofundadas em 2002, quando praticamente todos os grandes jornais deram um tratamento bastante equilibrado aos candidatos finalistas, Lula e Serra (ALDÉ, 2003). A exceção, mais uma vez, foram as revistas semanais que se dividiram em seu apoio político, com a Veja, engajada na campanha do candidato peessedebista, a Carta Capital na campanha do candidato petista, e a Época e a Isto é mantidas neutras (AZEVEDO, 2004b). Na área dos grandes jornais, O Estado de S. Paulo apoiou explicitamente o candidato oficial, mas os dois outros diários de expressão nacional (Folha de S. Paulo e O Globo) se mantiveram formalmente neutros na disputa. Mesmo no caso do Estado de S. Paulo, a tendência observada nos pleitos anteriores de uma cobertura mais equilibrada foi mantida em todos os jornais, sinalizando a propensão dos grandes diários em consolidar uma política de diversidade interna compatível com a exigência do jornalismo comercial de oferecer informações mais objetivas ao leitor. A grande novidade do pleito foi, de longe, a cobertura extensa e intensiva realizada pelas redes de televisão, especialmente a Rede Globo, que agendou diversos debates, realizou várias reportagens temáticas sobre o pleito e colocou a competição eleitoral no centro do seu telejornalismo obedecendo estritamente às normas de equilíbrio na cobertura das candidaturas (MIGUEL, 2003, 2004 e 2005; PORTO, BASTOS e VASCONCELOS, 2004). É claro que o equilíbrio não pode ser visto como uma decisão editorial, pois é compulsoriamente ditado pela rigorosa legislação em vigência. Mas, o grande volume de notícias, as reportagens temáticas e a realização dos debates, enfim, a decisão de conceder grande visibilidade ao pleito, foram claramente decisões jornalísticas internas que alteraram o perfil tradicional da cobertura da Rede Globo, uma emissora sempre acusada de favorecer pela visibilidade ou invisibilidade os candidatos apoiados pela família Marinho. 
Tabela 9

Presença da disputa eleitoral no Jornal Nacional em 1998/2002

\begin{tabular}{|l|c|c|}
\hline & 1998 & 2002 \\
\hline Semanas sob análise & 12 & 14 \\
\hline Edições do Jornal Nacional no período & 72 & 84 \\
\hline \multirow{2}{*}{ Edições com reportagens sobre as eleições } & 26 & 82 \\
& $(36,1 \%)$ & $(97,6 \%)$ \\
\hline Tempo total do Jornal Nacional no período & $27: 53: 59$ & $43: 57: 14$ \\
\hline \multirow{2}{*}{ Tempo sobre eleições presidenciais } & $1: 16: 34$ & $12: 55: 50$ \\
& $(4,6 \%)$ & $(29,4 \%)$ \\
\hline Tempo sobre eleições estaduais e outros temas de política & $0: 23: 49$ & $2: 34: 59$ \\
brasileira & $(1,4 \%)$ & $(5,9 \%)$ \\
\hline Tempo de "debate eleitoral" & $0: 10: 24$ & $8: 16: 51$ \\
& $(0,6 \%)$ & $(18,8 \%)$ \\
\hline \multirow{2}{*}{ Tempo total dos sound bites dos candidatos à presidência } & $0: 07: 37$ & $2: 26: 50$ \\
& $(0,5 \%)$ & $(5,6 \%)$ \\
\hline
\end{tabular}

Fonte: MIGUEL (2003, p. 9).

Obs.: (a) Período entre o final da Copa do Mundo e a votação do primeiro turno.

(b) Excluídas as manchetes e as chamadas ao final de cada bloco.

(c) Reportagens sobre articulações políticas dos partidos e candidatos, eventos de campanha, entrevistas dos candidatos, propostas de governo etc.

\section{Conclusão}

O nosso sistema de mídia não é estático e apresenta mudanças e transformações que devem ser notadas pelo impacto potencial na relação com o sistema político e na dinâmica democrática, especialmente num contexto de um sistema de mídia com baixa diversidade externa e sem um jornalismo político e/ou partidário expressivo no plano nacional que ofereça ao leitor perspectivas políticas competitivas.

Entre as mudanças apontadas ao longo deste texto está a consolidação do jornalismo comercial e o correspondente fortalecimento de uma política orientada para a diversidade interna. Esses dois aspectos estão obviamente correlacionados e é possível especular que, a longo prazo, se consolide do mesmo modo um jornalismo de informação em detrimento do jornalismo de opinião e, num quadro de um pluralismo partidário moderado que parece estar também em processo de cristalização, um jornalismo político mais aberto à pluralidade política e mais balanceado em relação aos atores políticos. Além disso, tem sido bastante relevante para a ampliação da diversidade interna a profissionalização do jornalista, um processo já inteiramente consolidado, e a presença de meios de crítica da mídia bastante ativa, como o Observatório da Imprensa, e a introdução da figura do ombudsman adotada por alguns jornais, como a Folha de S. Paulo. Quanto à televisão, 
um meio fortemente regulado pela legislação eleitoral, comparando a cobertura eleitoral de 1989 e a dos anos recentes, não há dúvidas de que esse meio se democratizou, pelo menos nos períodos eleitorais. A opção da Rede Globo de investir fortemente na cobertura eleitoral, como fez em 2002, poderá ser uma tendência irreversível induzida pela competição comercial e jornalística entre os veículos eletrônicos e pela consolidação da nossa cultura democrática.

Em síntese, as mudanças em curso, em boa parte já registradas pela literatura mais recente sobre o comportamento da mídia nos processos eleitorais, ainda que não tenham alterado as características centrais do nosso sistema de mídia representam avanços, e poderão contribuir para nos deixar mais próximos da idéia de um pluralismo regulado (THOMPSON, 1999, p. 209) em que as funções mais básicas da imprensa em uma democracia, como vigiar e fiscalizar o poder, promover o debate pluralista e mobilizar civicamente o cidadão sejam, de fato, efetivas entre nós. 


\section{Referências Bibliográficas}

ABREU, A. A. A modernização da imprensa (1970-2000). Rio de janeiro: Jorge Zahar, 2002.

AGUIAR, C. B. A imprensa e as eleições de 1989: imagens e atores da política. Comunicação \& Política, Rio de Janeiro, v. 1, n. 3, p. 179-194, abril/julho 1995.

ALBUQUERQUE, A. A campanha presidencial no Jornal Nacional: observações preliminares. Comunicação \& Política, Rio de Janeiro, v. 1, n. 1, p. 23-40, agosto/novembro 1994.

ALDÉ, A. As eleições presidenciais de 2002 nos jornais. Alceu - Revista de Comunicação, Cultura e Política, Rio de Janeiro, v. 3, n. 6, p. 23-45, 2003.

AZEVEDO, F. A. Imprensa, campanha presidencial e agenda da mídia. In: RUBIM, A. A. C. (ed.). Mídia e eleições 98. Salvador: Edições Facom, 2000, p. 31-56.

. Agendamento da política. In: RUBIM, A. A. C. Comunicação e política: conceitos e abordagens. São Paulo: Editora Unesp, 2004a, p. 41-71.

. As revistas semanais e a cobertura das eleições presidenciais de 2002. Apresentado no VII BRASA - Brazilian Studies Association, Rio de Janeiro, 2004b. 25 p.

AZEVEDO, F. A.; RUBIM, A. A. C.Mídia e política no Brasil. Lua Nova-Revista de Cultura e Política, São Paulo, n. 43, p. 189-216, 1998.

CHAIA, V. Eleições no Brasil: o medo como estratégia política. In: RUBIM, A. A. C. (org.). Eleições presidenciais em 2002 no Brasil: ensaios sobre mídia, cultura e política. São Paulo: Hacker, 2004, p. 29-52.

DAHL, R. Polyarchy: participation and opposition. New Haven: Yale University Press, 1971.

FIGUEIREDO, R. R. Mídia e eleições: cobertura jornalística da campanha presidencial de 1994. Opinião Pública, Campinas, v. 5, n. 1, p. 44-53, 1998.

FRASER, N. Rethinking the public sphere: a contribution to the critique of actually existing democracy. In: CALHOUN, C. (ed.). Habermas and the public sphere. Cambridge, MA: MIT Press, 1992, p. 109-142. 
GUIMARÃES, C.; VIEIRA, R. A. A. Meios de comunicação de massa e eleições: um experimento brasileiro. Comunicação \& Política, Rio de Janeiro, v. 1, n. 9, p. 147-158, 1989.

GUNTHER, R.; MUGHAN, A. Democracy and the media: a comparative perspective. New York: Cambridge University Press, 2000.

HABERMAS, J. Mudança estrutural da esfera pública. São Paulo: Tempo Brasileiro, 1984.

HALLIM, D. C.; MANCINI, P. Comparing media systems: three models of media and politics. New York: Cambridge University Press, 2004.

JORGE, V. L. Os meios de comunicação de massa nas campanhas eleitorais. Comunicação \& Política, Rio de Janeiro, v. 4, n. 1, p. 126-133, janeiro/abril 1997.

LIMA, V. A. Televisão e política: hipótese sobre a eleição presidencial de 1989. Comunicação \& Política, São Paulo, v. 9, n. 11, p. 29-54, abril/junho 1990. . Mídia, teoria e política. São Paulo: Fundação Perseu Abramo, 2001.

LUSTOSA, I. O nascimento da imprensa brasileira. Rio de Janeiro: Jorge Zahar, 2003.

MAIA, R. C. M. Mídia e deliberação pública: mediações possíveis. 2002. Apresentado no XI Encontro Anual da Compós, Rio de Janeiro, 2002. 16 p.

Dos dilemas da visibilidade midiática para a deliberação pública. 2003. Apresentado no XII Encontro Anual da Compós, Recife, 2003. 23 p.

MATTOS, S. Mídia controlada: a história da censura no Brasil e no mundo. São Paulo: Paulus, 2005.

MIGUEL, L. F. Mídia e eleições: a campanha de 1998 na Rede Globo. Dados, v. 42, n. 2, p. 253.276, 1999. Política e mídia no Brasil: episódios da história recente. Brasília: Plano, 2002.

Discursos cruzados: telenoticiários, HPEG e a construção da agenda eleitoral. 2003. Apresentado no XII Encontro Anual da Compós, Recife, 2003. 
. A descoberta da política: a campanha de 2002 na Rede Globo. In: RUBIM, A. A. C.

(org.). Eleições presidenciais em 2002 no Brasil: ensaios sobre mídia, cultura e política. São Paulo: Hacker, 2004, p. 91-105.

Televisão e construção da agenda eleitoral no Brasil. Diálogos Latinoamericanos, Aarhus, v. 10, p. 142-156, 2005.

PORTO, M.; BASTOS, B.; VASCONCELOS, R. A televisão e o $1^{\circ}$ turno das eleições presidenciais de 2002: análise do JN e do horário eleitoral. In: RUBIM, A. A. C. (org.). Eleições presidenciais em 2002 no Brasil: ensaios sobre mídia, cultura e política. São Paulo: Hacker, 2004, p. 68-90.

RUBIM, A. A. C. Medios, política y elecciones brasileñas de 1989 y 1994 . Dialogos de la Comunicación, Lima, v. 1, n. 42, p. 18-24, 1995.

RUBIM, A. A. C; COLLING, L. 2004. Mídia e eleições presidenciais no Brasil pós-ditadura. Comunicação e Política, Rio de Janeiro, v. 22, n. 3, p. 169-189.

SARTORI, G. Partidos e sistemas partidários. Brasília: Ed. Universidade de Brasília; Rio de Janeiro: Zahar, 1982.

SOARES, M. Construindo o significado do voto: retórica da propaganda política pela televisão. Tese de Doutoramento. Escola de Comunicações e Artes da Universidade de São Paulo, São Paulo, 1997.

SODRÉ, N. W. História da imprensa no Brasil. 4ª ed. Rio de Janeiro: Mauad, 1999.

THOMPSON, J. B. A mídia e a modernidade: uma teoria social da mídia. $2^{\mathrm{a}}$ ed. Petrópolis: Vozes, 1999.

Recebido para publicação em março de 2006. Aprovado para publicação em março de 2006. 